\title{
Caracterização de argamassas produzidas com cinza do bagaço de cana-de-açúcar
}

\author{
Characterization of mortars produced with sugarcane ash ash \\ Renato Michael Zanella ${ }^{1}$; Gabriella Faina Garcia ${ }^{2}$; Paulo Roberto Garcia ${ }^{3}$ \\ ${ }^{1}$ Engenheiro Civil, Universidade de Uberaba, Uberaba, Minas Gerais, Brasil. E-mail: zanellarenato@hotmail.com \\ ${ }^{2}$ Engenheira Mecânica, Universidade Federal de São Carlos, São Carlos, São Paulo, Brasil. E-mail: \\ gabifgarcia@gmail.com \\ ${ }^{3}$ Professor de Engenharia Civil, Universidade Federal do Triângulo Mineiro, Uberaba, Minas Gerais, Brasil. E-mail: \\ paulo.garcia@uftm.edu.br
}

RESUMO: Nos últimos anos, percebeu-se uma preocupação da sociedade com a preservação do meio ambiente e, consequentemente, com o crescente acúmulo de resíduos e dejetos de diferentes origens. Dentre esses resíduos, a cinza produzida a partir da queima do bagaço da cana-de-açúcar vem ganhando muita importância nesse cenário, já que se trata de uma fonte alternativa de energia renovável e sustentável. Assim, o objetivo principal deste trabalho foi caracterizar e analisar a influência da cinza do bagaço de cana-de-açúcar na resistência à compressão e na absorção de água por capilaridade de argamassas de cimento Portlad. As cinzas do bagaço de cana-deaçúcar e a areia utilizada nos ensaios foram caracterizadas quanto à sua distribuição granulométrica e massa específica. Foram moldados diversos corpos-de-prova de argamassas com substituição de 0,30,50 e 100\% da areia utilizada como agregado miúdo por cinzas do bagaço de cana-de-açúcar. Foi utilizada como comparador a argamassa comum com substituição de $0 \%$. O ensaio de resistência à compressão foi realizado após 3,7 e 28 dias da moldagem dos corpos-de-prova e o ensaio de absorção de água por capilaridade foi realizado após 28 dias, no intervalo de 3h, 6h, 24, 48h e 72h após a colocação dos corpos-de-prova em contato com a água. Os resultados mostram que a cinza do bagaço de cana-de-açúcar apresenta melhorias significativas, tanto para resistência à compressão, quanto para a absorção de água por capilaridade nas argamassas. Assim, conclui-se que a cinza do bagaço de cana-de-açúcar pode ser utilizada em substituição à areia fina na fabricação de argamassas de cimento Portland.

Palavras-chave: Areia; Argamassa; Cinza do Bagaço de Cana-de-açúcar; Sustentabilidade.

ABSTRACT: In recent years, there has been a concern of society with the preservation of the environment and, consequently, with the growing accumulation of waste and waste of different origins. Among these residues, ash produced from the burning of sugarcane bagasse has been gaining much importance in this scenario, since it is an alternative source of renewable and sustainable energy. Thus, the main objective of this work was to characterize and analyze the influence of ash from sugarcane bagasse on the compressive strength and water absorption by capillarity of Portlad cement mortars. The ashes of the sugarcane bagasse and the sand used in the tests were characterized as to their granulometric distribution and specific mass. Several mortar specimens with 0,30, 50 and 100\% of the sand used as a small aggregate were cast by ash from the sugar cane bagasse. The mortar was used as a comparator with $0 \%$ substitution. The compressive strength test was performed after 3,7 and 28 days of the molding of the specimens and the capillary water absorption test was performed after 28 days, in the interval of $3 h, 6 h, 24$, $48 \mathrm{~h}$ and $72 \mathrm{~h}$ after placing the specimens in contact with water. The results show that sugarcane bagasse ash presents significant improvements, both for compressive strength and for water absorption by capillarity in mortars. Thus, it is concluded that the sugarcane bagasse ash can be used in substitution for fine sand in the manufacture of Portland cement mortars.

Keywords: Sand; Mortar; Sugarcane bagasse ash; Sustainability. 
INTRODUÇÃO

Para a implantação de uma Usina sucroalcooleira, faz-se necessária a realização de estudos desde o cultivo da cana-de-açúcar e da produção de seus derivados. Primeiramente transformada em açúcar, a cana de açúcar ocupa um importante papel na economia, tendo o Brasil como líder mundial na produção de açúcar e álcool. Porém, mesmo após séculos de convívio com a agroindústria canavieira, somente no século $\mathrm{XX}$, o Brasil descobriu no álcool uma opção energética viável. De todos os resíduos da unidade industrial sucroalcooleira, o bagaço é um dos atrativos de maior poder na geração energética, o que faz a principal fonte energética do processo produtivo da fabricação do açúcar e do álcool. Para cada tonelada de bagaço que alimenta o processo de cogeração são produzidos aproximadamente $25 \mathrm{~kg}$ de cinza residual. Atualmente, a destinação das cinzas do bagaço da cana-de-açúcar (CBC) é um dos problemas enfrentados pelos administradores das usinas. A fuligem gerada no processo é recolhida com técnicas de lavagem e decantação e, juntamente com a cinza de caldeira, constituem-se em resíduos finais do processo industrial, no qual não há possibilidade de redução deles. As pesquisas nessa área apontam a necessidade de otimização do processo para a transformação desse resíduo em um material reativo ou pozolânico. Sofia Araújo Lima et al (2011).

Existe grande preocupação da sociedade com a preservação do meio ambiente e, consequentemente, com o crescente acúmulo de resíduos e dejetos de diferentes origens.

Uma das possíveis soluções para essa questão é a incorporação da cinza do bagaço da cana-de-açúcar em substituição ao agregado miúdo (areia) utilizado na fabricação de argamassa e concreto de cimento Portland. Com a reciclagem dessa cinza, pretende-se reduzir 0 volume de resíduos destinados a aterros sanitários. Consequentemente, as usinas de cana-de-açúcar, que ao fornecer as cinzas, além de resolver parte de seu problema como a estocagem desse resíduo que ocupa grande espaço no pátio e despesas com transporte para descarte em aterros, darão um destino racional a esse subproduto. No entanto, torna-se fundamental realizar estudos que busquem avaliar as potencialidades da cinza da cana-de-açúcar como agregado miúdo, com objetivo de verificar a possibilidade futura da utilização desse material como suplemento na fabricação de argamassas de cimento Portland.Torna-se bem claro que a CBC deve ser aplicada na propria usina onde ocorre o processo de transformação dos produtos em função do alto custo do transporte

A utilização de materiais pozolânicos combinados com cimento para obter concretos mais duráveis e econômicos faz parte do objetivo de tecnologistas da área da construção civil em todo o mundo (Sofia Araújo Lima et al (2011).

Pozolanas são materiais silicosos ou sílico-aluminosos, que por si só possuem pouca ou nenhuma atividade aglomerante hidráulica. Entretanto, quando preparados adequadamente (moídos), exibem a propriedade de reagirem em meio aquoso e a temperatura ambiente com o hidróxido de cálcio $(\mathrm{Ca}(\mathrm{OH}) 2)$, proporcionando a formação de novos compostos, com propriedades aglomerantes (cimentíceas) e, portanto, insolúveis em água. As pozolanas, frequentemente são, mais baratas do que o cimento Portland que elas substituem e possuem a característica de uma hidratação lenta e baixa taxa de desenvolvimento de calor. Isso é muito importante na construção em massa, o que justifica porque o cimento Portland-pozolana ou uma substituição parcial do cimento Portland pela pozolana é bastante utilizado. 
De acordo com Kawabata (2008) a substituição parcial do cimento Portland da composição de argamassas ou concretos por outros materiais pozolânicos, tais como a cinza de casca de arroz e cinza do bagaço de cana-de-açúcar, estará contribuindo para uma construção sustentável para a sociedade.

\section{METODOLOGIA}

A metodologia adotada foi a utilização de ensaios de ruptura e de permeabilidade. As cinzas do bagaço de cana-de-açúcar e a areia utilizadas nos ensaios foram caracterizadas quanto à sua distribuição granulométrica e massa específica. Foram moldados diversos corpos de prova de argamassas com substituição de 0\%, 30\%, 50\% e $100 \%$ da areia utilizada como agregado miúdo por cinzas do bagaço de cana-de-açúcar. Foi utilizada, como comparador, a argamassa comum com substituição de $0 \%$.

\section{Análise granulométrica da areia e da Cinza do Bagaço de Cana (CBC)}

O ensaio da composição granulométrica do agregado miúdo foi realizado conforme a NBR-7217 (1987).

Foram coletadas amostras de areia e CBC utilizada para fabricação das argamassas. Elas foram peneiradas e classificadas quanto à sua composição granulométrica, que é a proporção relativa (expressa em porcentagem) dos diferentes grãos que constituem o material, podendo ser expressa pelo material retido nas peneiras, pelo material que passa ou pela quantidade acumulada.

O ensaio da determinação granulométrica teve como objetivo principal a determinação da distribuição dos grãos que formam os agregados por tamanho, sendo eles:

- Dimensão máxima característica: abertura $(\mathrm{mm})$ correspondente a uma percentagem retida acumulada $\leq 5 \%$ em massa;

- Módulo de Finura: soma das porcentagens retidas acumuladas nas peneiras da série normal, dividido por 100 ;

- Materiais pulverulentos: partículas minerais com dimensão inferior a $0,075 \mathrm{~mm}$, incluindo os materiais solúveis em água presentes nos agregados.

De acordo com a NBR 7211(1983) e com o valor do módulo de finura, pode-se classificar a areia e a CBC a que classe de areia ela pertence, como muito fina, fina, média ou grossa.

\section{Determinação da Massa Específica da areia para a execução da argamassa da CBC}

Para determinar a massa específica da CBC e da areia utilizadas para fabricação das argamassas, foi necessária a coletar amostras desses materiais segundo NBR 7216 (1996). As amostras foram peneiradas e foram utilizadas para o ensaio somente os materiais passantes nas peneiras ABNT $n^{\circ} 16$, conforme a Figura 1. 
Em seguida, esses materiais foram secos em estufa entre $100^{\circ} \mathrm{C}$ a $110^{\circ} \mathrm{C}$, até a constância de massa. Após isso, a execução do ensaio foi realizada segundo a NBR 9776 (1987) utilizando-se o frasco de Chapman.

Figura 1. CBC e areia que foram utilizadas na fabricação da argamassa

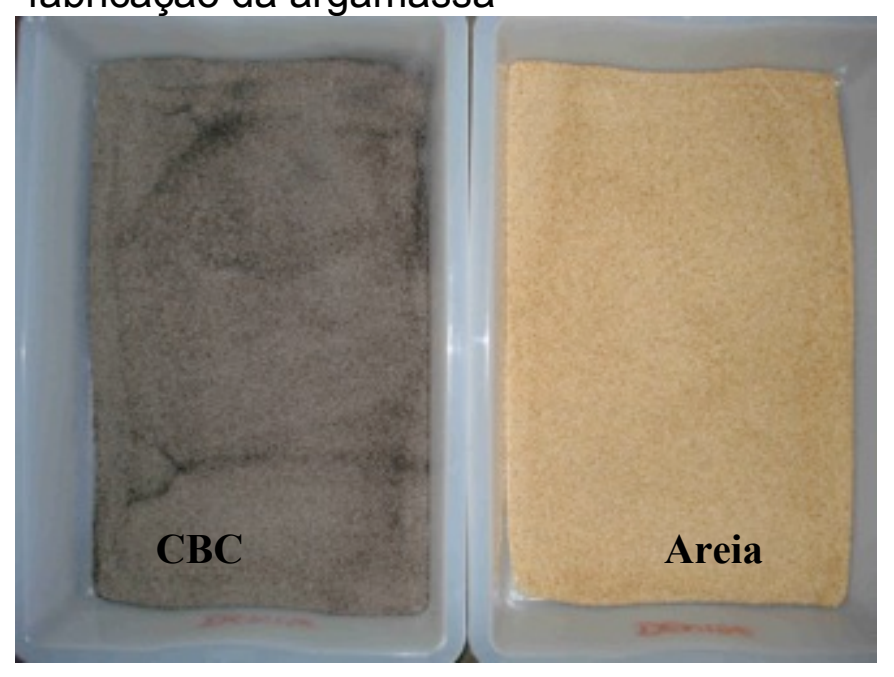

A massa específica é a relação entre a massa do agregado e o volume de seus grãos, não considerando o volume dos espaços intergranulares (volume de vazios). Seu valor é utilizado no cálculo do consumo de materiais em concretos e argamassas.

\section{Moldagem dos Corpos-de-prova}

Foram moldados, em laboratório, diversos corpos-de-prova de argamassa, de acordo com a norma NBR 5738 (1994). Tanto a areia como a cinza do bagaço de canade-açúcar (CBC) foram secadas em estufa em $105^{\circ} \mathrm{C}$, para não haver a necessidade da correção do fator água/cimento $(\mathrm{a} / \mathrm{c})$ devido à influência da umidade natural do material.

A areia e a CBC foram peneiradas, sendo utilizada para fabricação das argamassas somente o material passante nas peneiras, normalizado pela ABNT.

As argamassas foram fabricadas com um traço de 1:3, relação água/cimento $(\mathrm{a} / \mathrm{c})$ de 0,65 , com substituição da areia utilizada como agregado miúdo por CBC nas proporções de 0,50 e 100\% do total do agregado miúdo utilizado na fabricação das argamassas. Foram moldados corpos-de-prova utilizando os seguintes materiais:

- Material 1 - M1: Argamassa fabricada com cimento Portland composto com pozolana - CPII-Z32, 0\% CBC + 100\% areia e água;

- Material 2 - M2: Argamassa fabricada com cimento Portland composto com pozolana - CPII-Z32, 50\% CBC + 50\% areia e água;

- Material 3 - M3: Argamassa fabricada com cimento Portland composto com pozolana - CPII-Z32, 100\% CBC + 0\% areia e água.

Para cada material foram moldados 15 corpos-de-prova cilíndricos de 0,05 m de diâmetro por $0,10 \mathrm{~m}$ de altura, sendo todos destinados ao ensaio de determinação da 
resistência à compressão simples. A cura adotada para o ensaio foi a cura saturada em tanque com adição de cal.

\section{Determinação da Resistência à Compressão Simples}

O ensaio para determinar a resistência à compressão simples das argamassas foi realizado segundo a norma NBR 7215 (1982).

Após a moldagem das argamassas, foi realizado o ensaio para determinar as cargas de ruptura em (kgf) de 15 corpos-de-prova de cada um dos materiais (M1, M2, M3) nas idades de 3, 7 e 28 dias após a moldagem, conforme a Figura 2. Para cada uma das idades, foram ensaiados 5 corpos-de-prova por vez.

Após terem sido identificadas as cargas de ruptura nas três idades, foram determinadas as suas respectivas médias, seguindo o critério de avaliação das médias conforme a norma NBR 7215 (1982). Os resultados da resistência à compressão simples foram expressos em (MPa). Então, as médias foram convertidas de (kgf) para (MPa) pela divisão da carga de ruptura pela área da seção do corpo-de-prova, conforme a Equação 1.

$$
M=\frac{C}{A}
$$

Em que $M$ é a média da resistência à compressão simples, em MPa; $C$ é a carga de ruptura, em $\mathrm{N}$ e A é a área da seção do corpo-de-prova, em $\mathrm{mm}^{2}$.

Figura 2: Rompimento dos corpos-de-prova aos três dias após a moldagem.

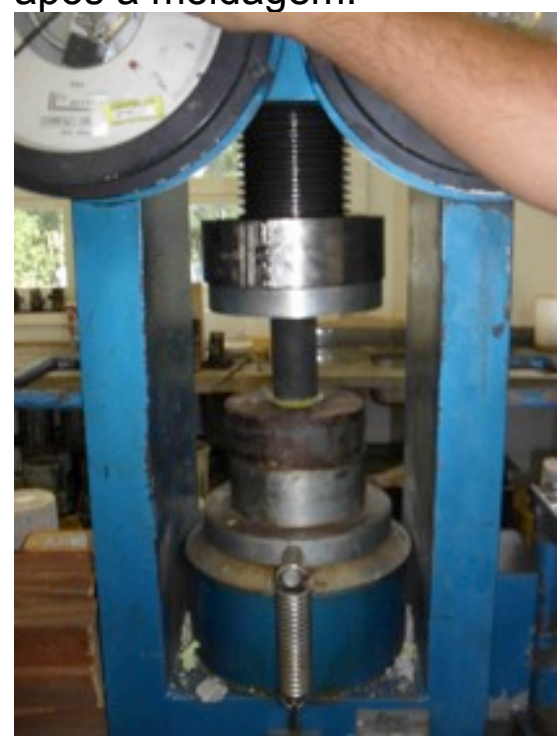

Após os testes, foram analisados se houve influência ou não da cinza do bagaço de cana-de-açúcar na resistência à compressão simples das argamassas $M 1, M 2, M 3$ nas idades de 3, 7 e 28 dias após a moldagem. 


\section{RESULTADOS E DISCUSSÃO}

Para a caracterização dos materiais utilizados nos ensaios da argamassa ora com areia ou CBC, foram realizados os seguintes testes: análise granulométrica e determinação da massa específica.

\section{Análise Granulométrica da Areia}

O ensaio da composição granulométrica da areia foi realizado conforme a NBR7217 (1987). Os resultados estão presentes na Tabela 1.

Tabela 1. Composição granulométrica da AREIA - NBR 7217 (1987).

\begin{tabular}{|c|c|c|c|c|c|c|c|}
\hline & & M1 (\%) & & & M2 (\%) & & \\
\hline $\begin{array}{c}\text { Peneira } \\
\text { (mm) }\end{array}$ & $\begin{array}{c}\text { Massa } \\
\text { Retida } \\
\text { (g) }\end{array}$ & $\begin{array}{c}\text { Retida } \\
(\%)\end{array}$ & $\begin{array}{c}\text { Acumula } \\
\text { da } \\
(\%)\end{array}$ & $\begin{array}{c}\text { Massa } \\
\text { Retida } \\
\text { (g) }\end{array}$ & $\begin{array}{c}\text { Retida } \\
(\%)\end{array}$ & $\begin{array}{c}\text { Acumula } \\
\text { da } \\
(\%)\end{array}$ & $\begin{array}{c}\text { Média } \\
\text { Acumula } \\
\text { da }(\%)\end{array}$ \\
\hline 4,8 & 0 & 0 & 0 & 0 & 0 & 0 & 0 \\
\hline 2,4 & 0 & 0 & 0 & 0 & 0 & 0 & 0 \\
\hline 1,2 & 33,1 & 3,3 & 3,3 & 34,9 & 3,5 & 3,5 & 3,4 \\
\hline 0,6 & 153,1 & 15,3 & 18,6 & 157,4 & 15,7 & 19,2 & 18,9 \\
\hline 0,3 & 426,0 & 42,6 & 61,2 & 428,3 & 42,8 & 62,0 & 61,6 \\
\hline 0,15 & 338,1 & 33,8 & 95,0 & 326,9 & 32,7 & 94,7 & 94,8 \\
\hline 0,075 & 37,9 & 3,8 & 98,8 & 41,8 & 4,2 & 98,9 & 98,9 \\
\hline Fundo & 11,8 & 1,2 & 100,0 & 10,7 & 1,1 & 100 & 100 \\
\hline
\end{tabular}

Tendo como base análise da Tabela 1, obtiveram-se os seguintes resultados:

- Dimensão máxima característica: abertura $(\mathrm{mm})$ correspondente a uma porcentagem retida acumulada $\leq 5 \%$ em massa: $1,2 \mathrm{~mm}$;

- Materiais pulverulentos: partículas minerais com dimensão inferior a $0,075 \mathrm{~mm}$, incluindo os materiais solúveis em água presentes nos agregados: 1,2 \%;

- Módulo de Finura: soma das percentagens retidas acumuladas nas peneiras da série normal, dividido por 100: $(3,4+18,9+61,6+94,8) / 100=1,79$.

De acordo com a NBR-7211(1983) e com o valor do módulo de finura pode-se classificar a areia como areia fina, ou seja, o módulo de finura se enquadra na faixa 1 (módulo de finura de 1,35 a 2,25) da tabela da norma referente.

\section{Análise Granulométrica da Cinza do Bagaço de Cana-de-açúcar - CBC}

O ensaio da composição granulométrica da CBC foi realizado conforme a NBR7217 (1987). Os resultados obtidos estão na Tabela 2. 
Tabela 2. Composição granulométrica da CBC - NBR 7217 (1987).

\begin{tabular}{|c|c|c|c|c|c|c|c|}
\hline \multirow[b]{2}{*}{$\begin{array}{l}\text { Peneira } \\
(\mathrm{mm})\end{array}$} & Massa & \multirow{2}{*}{$\begin{array}{c}\text { M1 (\%) } \\
\text { Retida } \\
(\%)\end{array}$} & \multicolumn{2}{|c|}{ 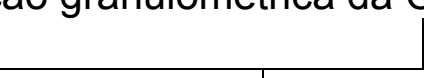 } & \multicolumn{3}{|c|}{ M2 (\%) } \\
\hline & $\begin{array}{l}\text { Massa } \\
\text { Retida } \\
\text { (g) }\end{array}$ & & $\begin{array}{c}\text { Acumulada } \\
(\%)\end{array}$ & $\begin{array}{c}\text { Massa } \\
\text { Retida } \\
\text { (g) }\end{array}$ & $\begin{array}{c}\text { Retida } \\
\text { (\%) }\end{array}$ & $\begin{array}{c}\text { Acumu } \\
\text { lada } \\
(\%)\end{array}$ & $\begin{array}{c}\text { Média } \\
\begin{array}{c}\text { Acumulada } \\
(\%)\end{array}\end{array}$ \\
\hline 4,8 & 4,0 & 0,4 & 0,4 & 3,9 & 0,4 & 0,4 & 0,4 \\
\hline 2,4 & 3,9 & 0,4 & 0,8 & 6,1 & 0,6 & 1,0 & 0,9 \\
\hline 1,2 & 16,9 & 1,7 & 2,5 & 18,1 & 1,8 & 2,8 & 2,65 \\
\hline 0,6 & 45,1 & 4,5 & 7,0 & 49,1 & 4,9 & 7,7 & 7,35 \\
\hline 0,3 & 282,0 & 28,2 & 35,2 & 279,9 & 28,0 & 35,7 & 35,5 \\
\hline 0,15 & 555,1 & 55,5 & 90,7 & 549,9 & 55,0 & 90,7 & 90,7 \\
\hline 0,075 & 80,0 & 8,0 & 98,7 & 80,1 & 8,0 & 98,7 & 98,7 \\
\hline Fundo & 13,0 & 1,3 & 100 & 12,9 & 1,3 & 100 & 100 \\
\hline
\end{tabular}

Tendo como base análise da Tabela 2, podem-se obter os seguintes resultados:

- Dimensão máxima característica: abertura $(\mathrm{mm})$ correspondente a uma porcentagem retida acumulada $\leq 5 \%$ em massa: $1,2 \mathrm{~mm}$;

- Materiais pulverulentos: partículas minerais com dimensão inferior a 0,075mm, incluindo os materiais solúveis em água presentes nos agregados: 1,7 \%;

- Módulo de Finura: soma das percentagens retidas acumuladas nas peneiras da série normal, dividido por 100: $(0,4+0,9+2,65+7,35+35,5+90,7) / 100=1,38$.

De acordo com a NBR-7211(1983) e com o valor do módulo de finura pode-se classificar a cinza do bagaço de cana-de-açúcar como areia fina, ou seja, o módulo de finura se enquadra na faixa 1 (módulo de finura de 1,35 a 2,25) da tabela da norma referente.

\section{Determinação da Massa Específica da Areia e da CBC}

O ensaio para a determinação da massa específica da areia e da CBC foi realizado segundo a NBR 9776 (1987), utilizando-se o frasco de Chapman.

Para a CBC utilizada na moldagem dos corpos-de-prova, o ensaio forneceu uma massa específica de $2,50 \mathrm{~g} / \mathrm{cm}^{3}$.

Para a areia utilizada na moldagem dos corpos-de-prova, o ensaio forneceu uma massa específica de $2,70 \mathrm{~g} / \mathrm{cm}^{3}$.

Já era esperado tal resultado, visto que a CBC possui uma parcela de material orgânico, que reduz a massa específica desse material em comparação à areia utilizada para fabricação das argamassas.

\section{Moldagem dos Corpos-de-Prova}

$\mathrm{Na}$ moldagem dos corpos-de-prova das argamassas em que foram utilizadas substituições de areia por CBC, notou-se diminuição da trabalhabilidade das argamassas com o aumento da porcentagem dessa substituição. Isso ocorreu porque a CBC apresenta menor granulometria do que as partículas da areia empregadas na mistura. 
Observou-se também maior coesão das argamassas com maior porcentagem de CBC em relação à argamassa com maior porcentagem de areia. Isso também pode ser explicado pela característica granulométrica dos materiais, onde a CBC apresenta módulo de finura menor do que o da areia.

As argamassas que foram moldadas com maiores teores de substituição da areia por CBC apresentaram uma coloração levemente mais escura, como se pôde observar na Figura 3.

Figura 3. Corpos-de-prova moldados com CBC e areia utilizada como agregado miúdo.

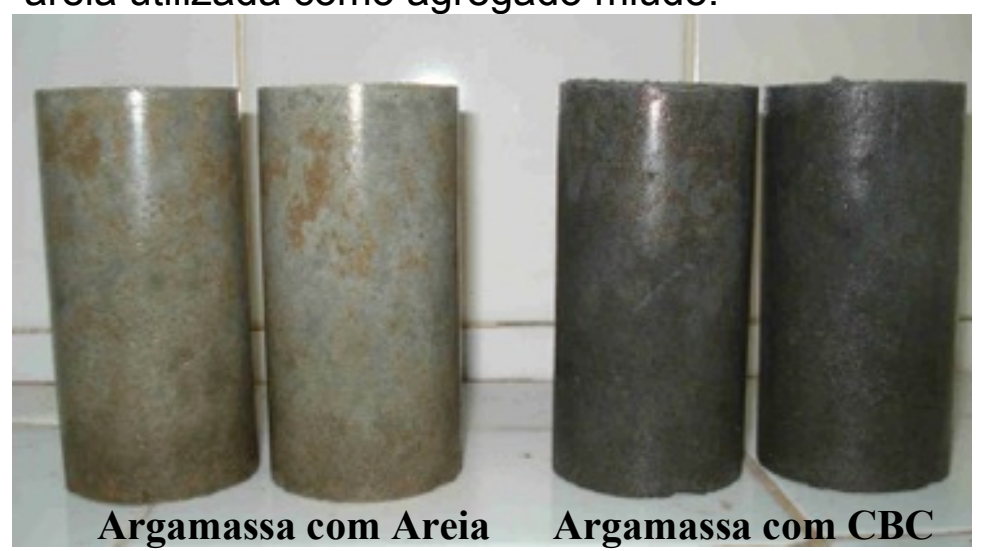

Determinação da Resistência à Compressão Simples das Argamassas

Na Tabela 3 e nas Figuras 4 e 5, são mostrados os valores médios da resistência à compressão simples dos corpos-de-prova das argamassas $M 1, M 2$ e $M 3$, nas idades de 3, 7 e 28 dias de rompimento após a moldagem dentro da normalização já citada.

Tabela 3. Valores médios da resistência à compressão simples das Argamassas, nas idades de 3, 7 e 28 dias após a moldagem.

\begin{tabular}{|c|c|c|c|}
\hline \multirow{3}{*}{$\begin{array}{c}\text { Idade } \\
\text { de } \\
\text { rompimento }\end{array}$} & \multicolumn{3}{|c|}{ Argamassas } \\
\hline & $\begin{array}{c}\text { M1 } \\
\text { Areia }\end{array}$ & $\begin{array}{c}\text { M2 } \\
50 \% \text { CBC+ } 50 \% \text { Areia }\end{array}$ & $\begin{array}{c}\text { M3 } \\
100 \% \text { CBC }\end{array}$ \\
\hline & \multicolumn{3}{|c|}{ Resistência à compressão simples (MPa)/ Absorção } \\
\hline Aos 3 dias & 4,994 & 5,494 & $6,243 / 2,95$ \\
\hline Aos 7 dias & 6,492 & 7,242 & $8,490 / 2,95$ \\
\hline Aos 28 dias & 8,990 & 9,989 & $11,487 / 2,96$ \\
\hline
\end{tabular}

Na Tabela 3, observa-se que, para o ensaio de resistência à compressão simples, as argamassas nas idades de 3, 7 e 28 dias, após a moldagem, apresentaram diferenças significativas.

Observa-se no gráfico da Figura 4 que a argamassa M3 (argamassa moldada com substituição da areia por CBC na proporção de 100\%), apresentou de forma 
significativa o maior valor médio de resistência à compressão simples para todas as idades de rompimento.

Figura 4. Valores médios da resistência à compressão simples das argamassas em diferentes dias de rompimento após a moldagem.

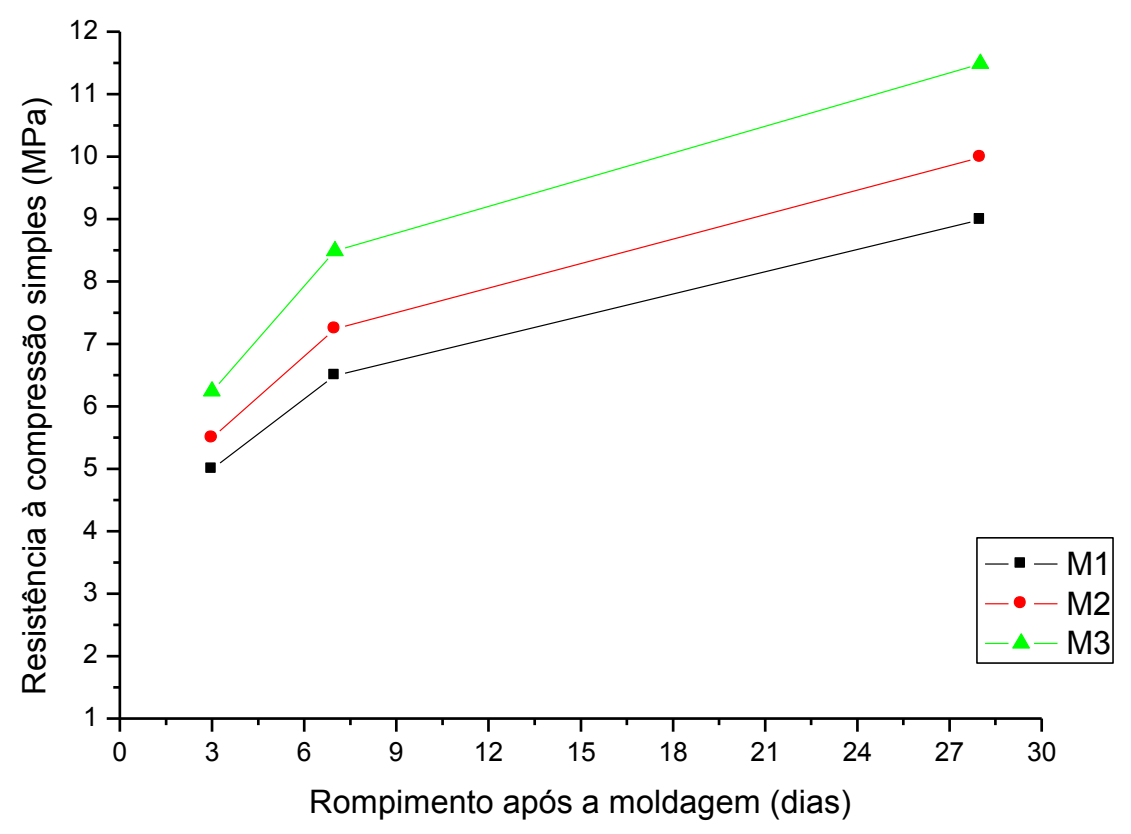

De acordo com a Tabela 3 e a Figura 4, o menor valor médio de resistência à compressão simples apresentado foi para a argamassa M1 (argamassa moldada com substituição da areia por CBC na proporção de $0 \%$ ), ou seja, a argamassa comum moldada somente com areia.

A argamassa M2 (argamassa moldada com substituição da areia por CBC na proporção de $50 \%$ ) apresentou valores médios de resistência à compressão quando comparada com as argamassas M1 e M3 para todas as idades de rompimento.

A argamassa M3 apresentou uma resistência à compressão simples de $21 \%$ superior ao da argamassa comum M1, para a idade de 28 dias após a moldagem, como pode ser observado na Tabela 3 e Figura 5.

Ao observar a Figura 5, percebe-se um aumento de resistência à compressão, à medida que o teor de substituição da areia por CBC é aumentado.até a proporção de $100 \%$.

Analisando os valores médios da resistência à compressão simples, na Figura 5, observa-se maior valor para a idade de 28 dias de rompimento, deferindo das demais. Isto se deve ao fato da argamassa já se encontrar totalmente endurecida após 28 dias da moldagem. 
Figura 5. Valores médios da resistência à compressão simples das argamassas em diferentes porcentagens de substituição da areia por CBC.

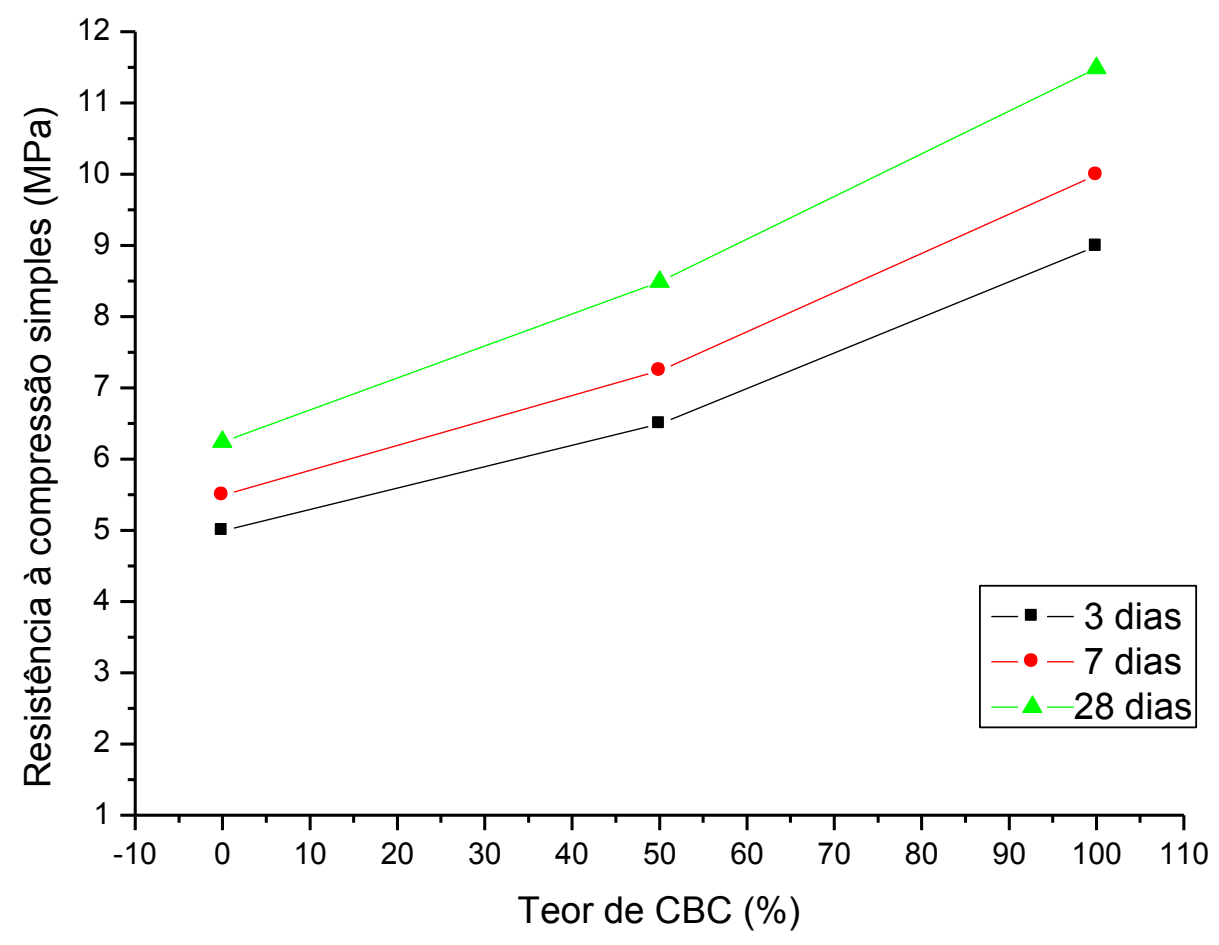

De acordo com a NBR-13281(2001), todas as argamassas ensaiadas (M1, M2 e M3) se enquadram na classe III (resistência à compressão aos 28 dias > 8,0MPa), podendo todas elas serem utilizadas na construção civil para o assentamento de tijolos e revestimentos de paredes e tetos.

Em relação à absorção nota-se que a mesma sofre pouca alteração independente da quantidade de CBC no concreto.

\section{CONCLUSÕES}

A cinza do bagaço de cana-de-açúcar apresenta aumento de resistência á compressão simples nas argamassas, quando a subtituição da areia por cinza de bagaço de cana-de-açúcar for de 50 e 100\%. Conforme foram aumentadas as proporções dessa substituição, obteve-se o aumento da resistência à compressão simples das argamassas.

A argamassa M3 que foi fabricada com substituição total da areia por cinza do bagaço de cana-de-açúcar apresentou um valor de $21 \%$ maior de resistência que a argamassa comum M1, após 28 dias.

Desse modo, pode-se afirmar que a cinza do bagaço de cana-de-açúcar apresentou melhorias significativas na resistência à compressão simples nas argamassas em que foram utilizadas, totalmente ou parcialmente, como agregado miúdo.

Finalmente, pôde-se concluir com esses estudos iniciais que as cinzas do bagaço de cana-de-açúcar, devidamente tratadas, têm grande potencial para serem utilizadas na substituição da areia fina para a confecção de argamassas destinadas a revestimento de 
paredes e tetos e assentamento de blocos e tijolos de construção. Porém, são necessários ainda outros ensaios e testes para comprovar de maneira mais eficiente afirmações, tais como: consumo de água para um mesmo abatimento, absorção de água por capilaridade e ensaios de durabilidade a longo prazo.

\section{REFERÊNCIAS}

ANAP - BRASIL - As influências da substituição de cimento por cinza de bagaço de cana-de-açucar(CBC) em concretos. V-9, nº 17 - ISSN-1984-3240, Tainara C. Ávila, Sérgio E. F. e Jorge L. Akasaki, 2016

ASSOCIAÇÃO BRASILEIRA DE NORMAS TÉCNICAS. NBR 5738: Moldagem e cura de corpos-de-prova cilíndricos ou prismáticos de concreto. Rio de Janeiro ,1994. 6 p.

ASSOCIAÇÃO BRASILEIRA DE NORMAS TÉCNICAS. NBR 7211: Agregados para concreto. Rio de Janeiro ,1983. 5 p.

ASSOCIAÇÃO BRASILEIRA DE NORMAS TÉCNICAS. NBR 7215: Determinação da resistência à compressão. Rio de Janeiro ,1996. 8 p.

ASSOCIAÇÃO BRASILEIRA DE NORMAS TÉCNICAS. NBR 7216: Amostragens de agregados. Rio de Janeiro ,1996. 4 p.

ASSOCIAÇÃO BRASILEIRA DE NORMAS TÉCNICAS. NBR 7217: Agregados Determinação da composição granulométrica. Rio de Janeiro, 1987. 3 p.

ASSOCIAÇÃO BRASILEIRA DE NORMAS TÉCNICAS. NBR 9776: Determinação da massa específica de agregado miúdo por meio do frasco Chapman. Rio de Janeiro, 1987. $3 \mathrm{p}$.

ASSOCIAÇÃO BRASILEIRA DE NORMAS TÉCNICAS. NBR 12653: Cimento Portland composto. Rio de Janeiro, 1991. 4 p.

ASSOCIAÇÃO BRASILEIRA DE NORMAS TÉCNICAS. NBR 13281: Argamassa para assentamento e revestimento de paredes e tetos - Requisitos. Rio de Janeiro, 2001. 3 p.

COIMBRA, M. A.; SANTOS, W. N. dos; MORELLI, M. R.. Recuperação de resíduos inorgânicos para a construção civil. Cerâmica, São Paulo , v. 48, n. 306, p. 4448, June 2002. DOI: http://dx.doi.org/10.1590/S0366-69132002000200001.Disponível em: <http://www.scielo.br/scielo.php?script=sci_arttext\&pid=S036669132002000200001\&lng=en\&nrm=iso>. ACESSO EM: 23 abr. 2019.

DO CARMO, J. B. M. Análise comparativa do desempenho de concretos compostos com sílica ativa e metacaulim face à resistência mecânica e à viabilidade econômica.2006. 154 f. Dissertação (Mestrado em Engenharia e Ciência dos Materiais) Universidade Federal do Paraná, Curitiba, 2006. 
LIMA A. S., Fernando do C., ROSA A., Juliana Petermann M.. Kleber F. P. Concretos com cinza do bagaço da cana-de-açúcar: avaliação da durabilidade por meio de ensaios de carbonatação e abrasão. Ambiente Construído, Porto Alegre, v. 11, n. 2, p. 201-212, abr./jun. 2011

FREITAS, E. S. Caracterização da cinza do bagaço da cana-de-açúcar do município de campos dos Goytacazes para uso na construção civil. 2005. 97 f. Dissertação (Mestrado em Engenharia Civil) - Universidade Estadual do Norte Fluminense Darcy Ribeiro - UENF, Campos dos Goytacazes - RJ, 2005.

KAWABATA, C.Y. Aproveitamento de cinzas da queima de resíduos agroindustriais na produção de compósitos fibrosos e concreto leve para a construção rural. 2008. 165 f. Tese (Doutorado) - Faculdade de Zootecnia e Engenharia de Alimentos, Universidade de São Paulo, Pirassununga, 2008.

ZARDO, A. M. et al. Utilização da cinza do bagaço de cana-de-açúcar como "filler" em compostos de fibrocimento. In: I CONFERÊNCIA LATINO-AMERICANA DE CONSTRUÇÃO SUSTENTÁVEL E X ENCONTRO NACIONAL DE TECNOLOGIA DO AMBIENTE CONSTRUÍDO, 2004, São Paulo, Brasil. Anais... São Paulo: conferência latino-americana de construção sustentável e x encontro nacional de tecnologia do ambiente construído - CLACS e ENTAC, 2004. 1 CD-ROM.

Recebido em: 30/10/2018

Aprovado em: 12/03/2019 